\title{
Intra-Field Variation of Prokaryotic Communities On and Below the Seafloor in the Back-Arc Hydrothermal System of the Southern Mariana Trough
}

\author{
Shingo Kato, Moriya Ohkuma, and Akihiko Yamagishi
}

\begin{abstract}
Deep-sea hydrothermal vents harbor diverse prokaryotes. There are a variety of habitat types in a deep-sea hydrothermal field, e.g., active and inactive chimneys, iron-rich mats, venting fluid and hydrothermal plume. Numerous studies have shown the diversity and composition of prokaryotic communities in individual habitats. However, it is still unclear whether and how the characteristics of prokaryotic communities in their respective habitats are different. Previously, we reported 16S rRNA genes in a variety of habitats, i.e., hydrothermally active and inactive chimneys, iron-rich mats, a vent fluid, crustal fluids from boreholes, as well as ambient seawater in a back-arc basin hydrothermal field of the Southern Mariana Trough. Here we summarize the prokaryotic communities in the collected samples at higher taxonomic resolution (up to family level) using the detected $16 \mathrm{~S}$ rRNA gene sequences and compare them using recently developed bioinformatics tools. The comparative analysis clearly highlights differences in prokaryotic communities among the habitat types on and below the seafloor in the Southern Mariana Trough. Furthermore, descriptions of cultured species and environmental clones close to the detected sequences provide valuable information for understanding of their distribution and potential of ecological roles in deep-sea hydrothermal fields.
\end{abstract}

\section{Keywords}

16S rRNA gene $\bullet$ Archaea $\bullet$ Back-arc basin $\bullet$ Bacteria $\bullet$ Chemosynthetic ecosystem $\bullet$ Deepsea hydrothermal vents $\bullet$ Prokaryotic community

The online version of this chapter (doi:10.1007/978-4-431-54865-2_24) contains supplementary material, which is available to authorized users.

S. Kato

Japan Collection of Microorganisms, RIKEN BioResource Center, Tsukuba, Ibaraki, Japan

Department of Molecular Biology, Tokyo University of Pharmacy and Life Science, 1432-1 Horinouchi, Hachioji, Tokyo 192-0392, Japan

M. Ohkuma

Japan Collection of Microorganisms, RIKEN BioResource Center, Tsukuba, Ibaraki, Japan

A. Yamagishi $(\bowtie)$

Department of Molecular Biology, Tokyo University of Pharmacy and Life Science, 1432-1 Horinouchi, Hachioji, Tokyo 192-0392, Japan

e-mail: yamagish@toyaku.ac.jp

\subsection{Introduction}

Deep-sea hydrothermal vents are oases for organisms on the vast seafloor. Hydrothermal fluids are rich in reduced chemical species, such as hydrogen, hydrogen sulfide, methane and ferrous iron, which support the growth of chemolithoautotrophs as energy sources. Chemolithoautotrophs are the primary producers in the chemosynthetic ecosystem in TAIGA, which is designated a great sub-seafloor river (Urabe et al. Chap. 1). Numerous studies have characterized the prokaryotic community structures in various habitat types, such as hydrothermally active chimneys (e.g., Flores et al. 2012a; Kato et al. 2010; Kormas et al. 2006; Nakagawa et al. 2005; Schrenk et al. 2003; Takai and Horikoshi 1999), inactive chimneys (Kato et al. 2010; Suzuki et al. 2004; 
Sylvan et al. 2012), iron-rich mats (e.g., Davis and Moyer 2008; Fleming et al. 2013; Forget et al. 2010; Kato et al. 2009a), and crustal fluids (Cowen et al. 2003; Huber et al. 2006; Kato et al. 2009b, 2013; Orcutt et al. 2011), in various deep-sea hydrothermal fields. Through such studies, interfield variation between prokaryotic community structures in deep-sea hydrothermal system habitats has been revealed (e.g., Takai et al. 2006; Flores et al. 2012a). However, intrafield variation of prokaryotic community structures among these habitat types is still poorly understood.

The Southern Mariana Trough (SMT) is an actively spreading back-arc basin that is located at the southern extension of the Izu-Bonin Arc (Seama et al. Chap. 17). Hydrothermal vents have been found on the back-arc spreading ridge and off-ridge seamounts in the SMT. Furthermore, in this field, several boreholes have been drilled by a seafloor-drilling instrument, the Benthic Multi-coring System (BMS) (Marumo et al. 2008). The tectonics and geology of the SMT and geochemistry of its hydrothermal fluids have been well studied (Seama et al. Chap. 17; Toki et al. Chap. 45). Therefore, the SMT is a model field for studying the relationships among tectonics, geology, geochemistry, and microbial ecology in many habitats including subseafloor environments.

We analyzed the prokaryotic community structures in a variety of samples collected in the SMT, such as active and inactive chimneys, iron-rich mats, hydrothermal fluid from an active vent and boreholes, and ambient seawater (Kato et al. 2009a, b, 2010). In particular, the chemosynthetic ecosystem supported by ferrous iron was found in the ironrich mats and crustal fluids (Kato et al. 2012). However, comprehensive comparative analyses of the prokaryotic community structures among the SMT samples have not been carried out. In this review, we summarize the prokaryotic community structures in the SMT samples at higher taxonomic resolution (up to family level) based on the $16 \mathrm{~S}$ rRNA gene sequences and compare them using recently developed bioinformatics tools. The results highlight the differences of prokaryotic communities on and below the seafloor in the SMT.

\subsection{Re-Analysis of 16S rRNA Gene Sequences}

The 16S rRNA gene sequences were recovered from ironrich mats (YS16 and YS18) (Kato et al. 2009a), active (AFhm, APcsc, APbsc, AAcs) and inactive chimneys (IPltc, IYdc, Inoc) (Kato et al. 2010; Kato et al. Chap. 9), crustal fluids obtained from boreholes (Fapm1a, Fapm1b, Papm3, F2apm1), a natural vent fluid (Fnv) and ambient seawater (Pasw and Fasw) (Kato et al. 2009b) in the SMT hydrothermal fields, i.e., Snail, Pika, Archaean, Kaiko and
Yamanaka sites (Suppl. 24.1). The map for these sampling sites is shown in previous reports (Kato et al. 2009a, b, 2010) and Seama et al. (Chap. 17). The crustal fluid samples of Fapm1a, Fapm1b and F2apm1 were collected from the same borehole APM01 in the Snail site. Fapm1a and Fapm1b were collected in March 2004. F2apm1 was collected in August 2005. The 16S rRNA gene sequences were analyzed using QIIME version 1.7.0 (Caporaso et al. 2010) for clustering into OTUs at a $97 \%$ similarity cut-off and for taxonomic affiliation of the OTUs. Any improper taxonomic affiliations by QIIME were modified manually as judged by the phylogenetic analysis described in previous reports (Kato et al. 2009a, b, 2010). It should be noted that the taxonomy within Archaea has not been standardized yet, and the affiliation for some archaeal groups based on the QIIME-equipped reference database is doubtful: for example, pMC1A4 and the related clones in Marine Benthic Group E (MBGE) was affiliated with Methanobacteriales. Therefore, the taxonomic affiliation of the detected clones was modified manually based on the archaeal phylogenetic tree as shown in Suppl. 24.2, which is provided in SILVA-Ref-NR database release 111 (Quast et al. 2012). A maximum-likelihood phylogenetic tree for Zetaproteobacteria was constructed by PhyML version 3.0 (Guindon et al. 2010). Coverage for each clone library was calculated using mothur version 1.2.8 (Schloss et al. 2009). Bacterial and archaeal community structures were compared by principal coordinate analysis (PCoA) using unweighted UniFrac (Lozupone and Knight 2005) equipped with QIIME. The sequencing process, i.e., DNA extraction, PCR, cloning and sequencing, was almost identical for all samples (Kato et al. 2009a, b, 2010). PCR was performed using a prokaryote-universal PCR primer set, Uni516F and Uni1406R, and an archaea-universal primer set, Arc8F and Uni1406R. Bacterial 16S rRNA gene sequences were dominant in the clone library data constructed using the prokaryote-universal PCR primer set (Kato et al. 2009a, b, 2010). Only the bacterial 16S rRNA gene sequences were extracted and used for bacterial community analyses in this study. To obtain more archaeal clones, we performed PCR clone analysis using the archaea-universal primer set in the previous studies (Kato et al. 2009a, b, 2010).

\subsection{Bacterial Community Structures}

Bacterial community structures in the SMT samples are summarized in Fig. 24.1. The relative abundance of each taxon in the libraries at the phylum level is shown in Fig. 24.1a. For Proteobacteria, the relative abundance in the class level (i.e., Alpha-, Beta-, Gamma-, Delta-, Epsilonand Zetaproteobacteria) is shown in Fig. 24.1b. For each proteobacterial class except Beta- and Zetaproteobacteria, 


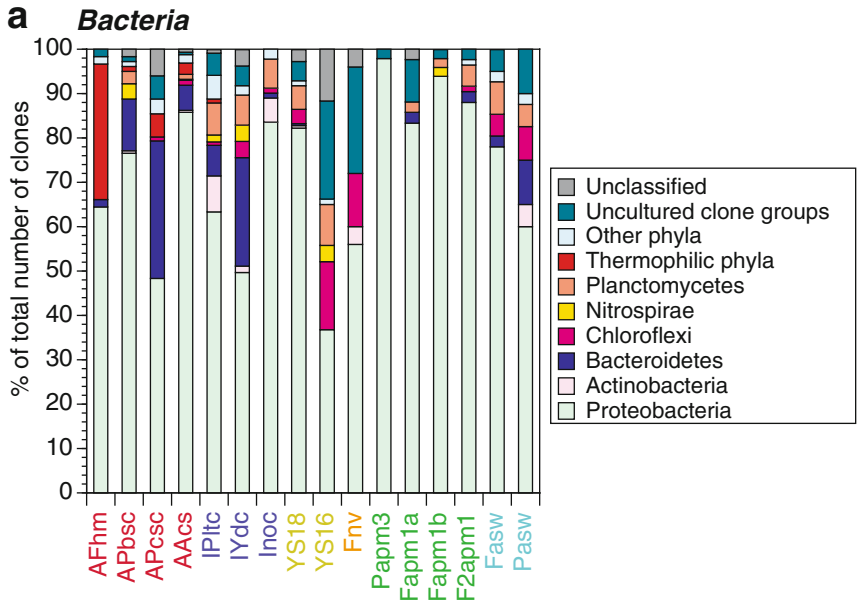

C Alphaproteo.

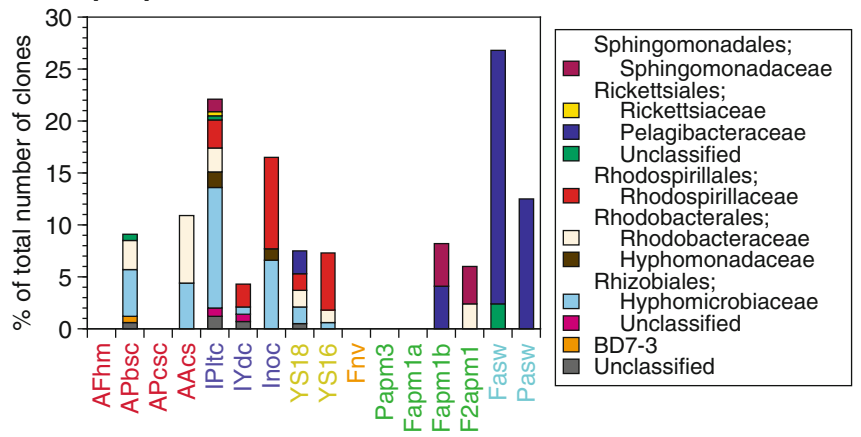

e Deltaproteo.

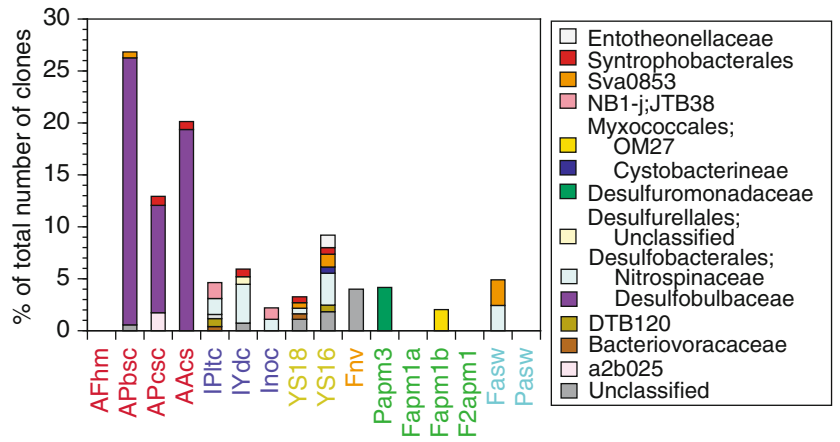

g Bacteroidetes

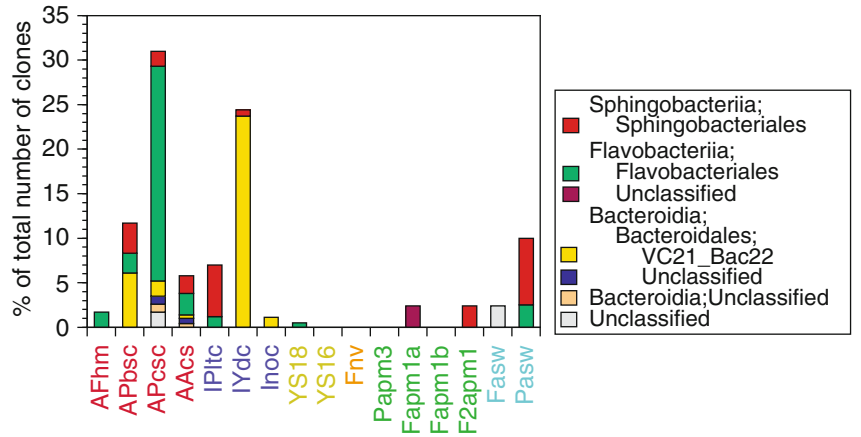

Fig. 24.1 Bacterial community structures based on the 16S rRNA gene clone libraries. The detection frequency of each taxon for (a) Bacteria, (b) Proteobacteria, (c) Alphaproteobacteria, (d) Gammaproteobacteria, (e) Deltaproteobacteria, (f) Epsilonproteobacteria, (g) Bacteroidetes, and (h) Uncultured clone groups are shown. (a) "Thermophilic phyla" include Aquificae, Caldithrix, Deinococcus-Thermus, Thermodesulfobacteria and Thermotogae, and "Other phyla" include

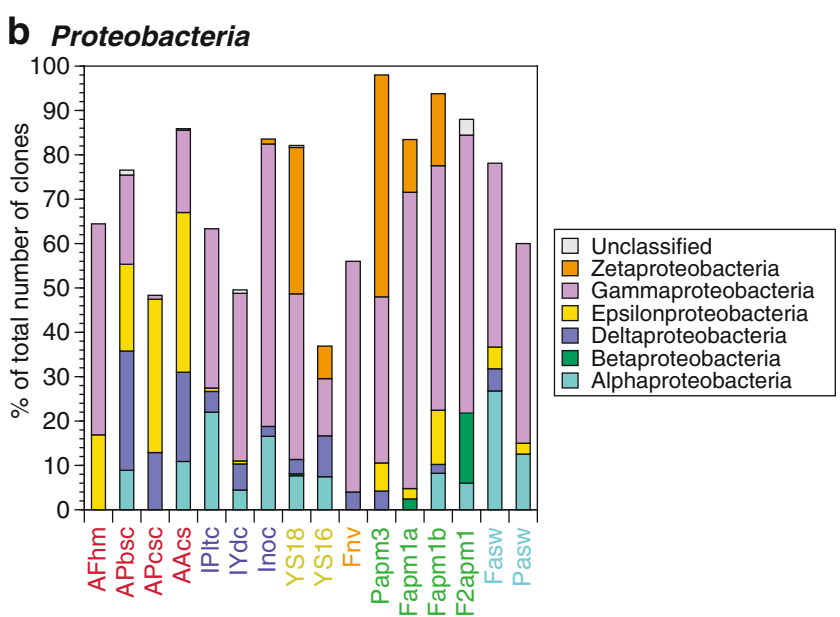

d Gammaproteo.
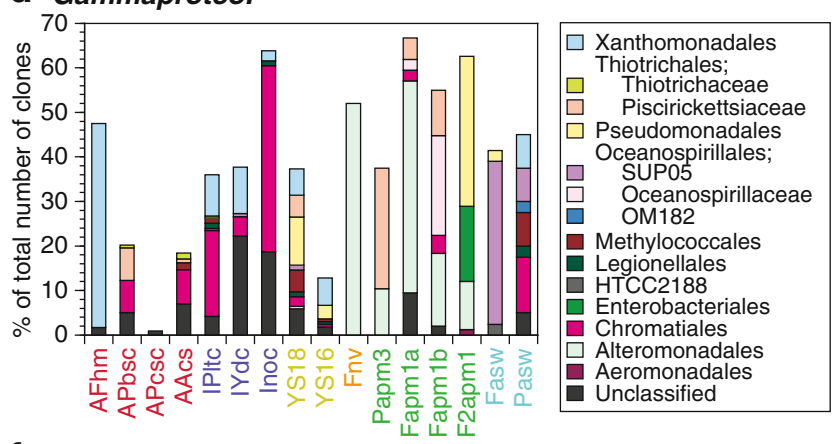

f Epsilonproteo.
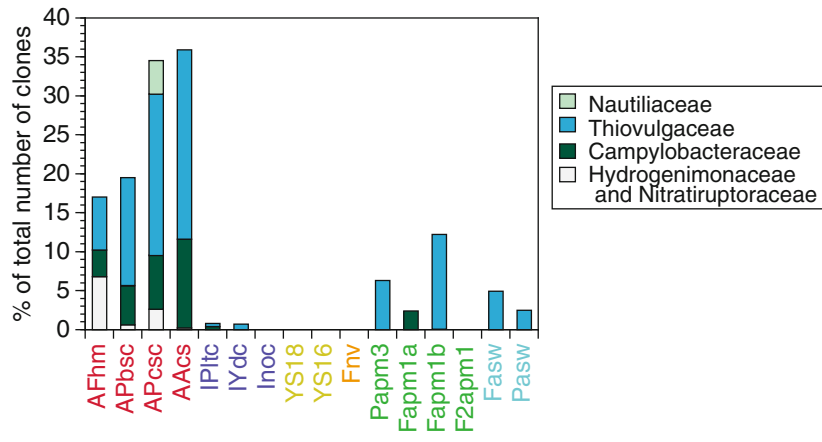

h Clone groups

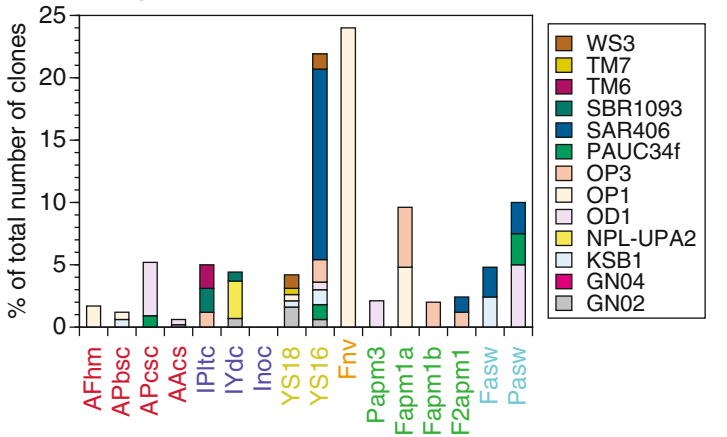

Chlamydiae, Chlorobi, Acidobacteria, Cyanobacteria, Firmicutes, Fusobacteria, Gemmatimonadetes, Spirochaetes and Verrucomicrobia. Colors of the sample ID indicate the sample types: red, active chimney; purple, inactive chimney; yellow, iron-rich mat; orange, natural vent fluid; green, crustal fluid; sky-blue, ambient seawater. See also Suppl. Table 24.1 for the sample description 
Table 24.1 Summary of dominant bacterial and archaeal taxa for each sample type

\begin{tabular}{|c|c|c|c|c|c|}
\hline $\begin{array}{l}\text { Sample } \\
\text { type }\end{array}$ & $\begin{array}{l}\text { Temperature } \\
\left({ }^{\circ} \mathrm{C}\right)^{\mathrm{a}}\end{array}$ & $\mathrm{pH}^{\mathrm{a}}$ & Abundant bacterial taxa $\mathrm{a}^{\mathrm{b}}$ & Abundant archaeal taxa ${ }^{\mathrm{b}}$ & $\begin{array}{l}\text { Inorganic } \\
\text { energy } \\
\text { sources }^{c}\end{array}$ \\
\hline $\begin{array}{l}\text { Active } \\
\text { chimney }\end{array}$ & $19-270$ & $2.9-6.4$ & $\begin{array}{l}\text { Aquificae, Thiovulgaceae }(\varepsilon), \text { Campylobacteraceae }(\varepsilon), \\
\text { Desulfobulbaceae }(\delta), \text { Xanthomonadales }(\gamma), \\
\text { Flavobacteriales (Bact) }\end{array}$ & $\begin{array}{l}\text { Thermococci, Archaeoglobi, } \\
\text { Thermoprotei, Aciduliprofundaceae, } \\
\text { THSCG, Korarchaeota }\end{array}$ & $\mathrm{H}_{2}, \mathrm{H}_{2} \mathrm{~S}$ \\
\hline $\begin{array}{l}\text { Inactive } \\
\text { chimney }\end{array}$ & $2-3$ & $7.6-8.1$ & Chromatiales $(\gamma), \mathrm{VC} 21 \_$Bac22 (Bact) & MGI, DHVEG-6 & $\mathrm{FeS}_{2}, \mathrm{NH}_{4}$ \\
\hline $\begin{array}{l}\text { Iron-rich } \\
\text { mat }\end{array}$ & $33-116$ & $5.8-6.7$ & Zetaproteobacteria, SAR406 & MCG, MBGE & $\mathrm{Fe}^{2+}$ \\
\hline $\begin{array}{l}\text { Crustal } \\
\text { fluid }\end{array}$ & $6-40$ & $6.4-7.3$ & $\begin{array}{l}\text { Zetaproteobacteria, Piscirickettsiaceae }(\gamma), \\
\text { Oceanospirillaceae }(\gamma), \text { Alteromonadales }(\gamma), \\
\text { Pseudomonadales }(\gamma)\end{array}$ & MCG, MGI & $\begin{array}{l}\mathrm{Fe}^{2+}, \mathrm{H}_{2} \mathrm{~S} \\
\mathrm{NH}_{4}\end{array}$ \\
\hline $\begin{array}{l}\text { Natural } \\
\text { vent fluid }\end{array}$ & $63-69$ & $6.2-6.3$ & Alteromonadales $(\gamma), \mathrm{OP} 1$ & MCG, MGBE, MGI & $\mathrm{H}_{2}$ \\
\hline $\begin{array}{l}\text { Ambient } \\
\text { seawater }\end{array}$ & $2-3$ & $7.6-8.1$ & Pelagibacteraceae $(\alpha)$, SUP05 $(\gamma)$ & MGI & $\mathrm{H}_{2} \mathrm{~S}, \mathrm{NH}_{4}$ \\
\hline
\end{tabular}

the relative abundance in the order or family level is shown in Fig. 24.1c-f. The relative abundance in Bacteroidetes and uncultured clone groups are shown in Fig. 24.1g, h. The dominant taxonomic groups for each sample type are summarized in Table 24.1 along with their environmental characteristics.

\subsubsection{Zetaproteobacteria}

Zetaproteobacteria were detected in the two iron-rich mat samples (YS16 and YS18), three crustal fluid samples (Papm3, Fapm1a and Fapm1b) and one inactive chimney sample (Inoc) (Fig. 24.1b). The relative abundance was up to $50 \%$ of the total number of clones. Davis and Moyer (2008) also detected Zetaproteobacteria in an iron-rich mat sample from the Snail site. McAllister et al. (2011) have shown that most of the zetaproteobacterial clones detected in the crustal fluids are not clustered with the other clones detected in the other samples, suggesting the presence of endemic zetaproteobacterial members in the crustal fluids in the SMT (Suppl. 24.3). Quantitative analyses have shown that Zetaproteobacteria is abundant (up to $30 \%$ of total prokaryotic cells) in prokaryotic communities in iron-rich mats and crustal fluids in the SMT (Kato et al. 2009a, b). The sole cultured species in Zetaproteobacteria was Mariprofundus ferrooxydans, a neutrophilic iron-oxidizing chemolithoautotroph (Emerson et al. 2007). Given that all or most of the Zetaproteobacteria are iron-oxidizers (Emerson et al. 2010; Fleming et al. 2013), any microbial ecosystem dominated by Zetaproteobacteria is supported by ferrous iron as the energy source (i.e., "iron-based ecosystem"). This is consistent with the thermodynamic calculation of bioavailable energy yields based on geochemical characteristics of the environments: the energy yield obtained from iron oxidation is comparable to or higher than that from oxidation of other reduced chemical species, such as hydrogen, hydrogen sulfide and methane (Kato et al. 2012).

Remarkably, iron-based ecosystems were found at both the Snail and Pika sites, even though their geological settings (on and off-ridge) are different (Seama et al. Chap. 17). Ironbased ecosystems also occur in deep-sea hydrothermal fields with other geological characteristics, such as the Loihi Seamount of Hawaii (Fleming et al. 2013), Tonga-Kermadec Arc (Forget et al. 2010; Hodges and Olson 2009), Lau basin (Li et al. 2012), Juan de Fuca Ridge (Davis et al. 2009) and

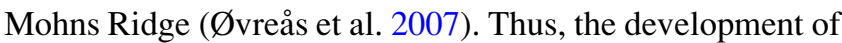
iron-based ecosystems seems to be independent of these geological differences. Kato et al. (2012) have suggested that higher concentration of ferrous iron than hydrogen sulfide, which can supply more energy for the growth of iron-oxidizers than sulfide-oxidizers, is needed for the development of ironbased ecosystems. In addition, the continuous supply of ferrous iron, the chemical conditions that make ferrous iron dissolve stably (i.e., low $\mathrm{pH}$, low $\mathrm{Eh}$ and low concentration of sulfide), and the temperature at which the iron-oxidizers can grow may be also important for the development of iron-based ecosystems. Iron-based ecosystems are likely to be widely distributed in environments that fulfill the above conditions on and below the seafloor. 


\subsubsection{Alphaproteobacteria}

The relative abundance of each family level taxon of Alphaproteobacteria differed among the sample types (Fig. 24.1c). Hyphomicrobiaceae were relatively abundant in some solid samples, i.e., active and inactive chimneys and iron-rich mats (Fig. 24.1c). Most of the clones in the Hyphomicrobiaceae were not close to the cultured species $(<92 \%$ of 16S rRNA gene similarity) and clustered with environmental clones detected in deep-sea basaltic rocks and sulfide chimneys (Kato et al. 2013; Santelli et al. 2008). Rhodospirillaceae were relatively abundant in the iron-rich mat and inactive chimney samples, but not detected in the active chimney samples (Fig. 24.1c). One of the closest cultured species for the clones in the Rhodospirillaceae was a magnetotactic bacterium Magnetovibrio blakemorei with $92 \%$ similarity (Bazylinski et al. 2013). The physiology of the uncultured bacteria in Hyphomicrobiaceae and Rhodospirillaceae was unclear; however, considering the sample types (i.e., sulfide chimneys, iron-rich mats and rocks on the seafloor) where they were detected, their presence was probably related to the presence of iron and/or sulfide minerals (such as goethite, pyrite, chalcopyrite and sphalerite (Ikehata et al. Chap. 22; Kakegawa et al. 2008; Masuda and Fryer, Chap. 21)).

In contrast, Sphingomonadaceae were relatively abundant in two crustal fluid samples (Fig. 24.1c). The detected clones of Sphingomonadaceae were close to Sphingomonas species ( $>97 \%$ similarity) including oligotrophs, which are widely distributed in nature. In the crustal aquifer, they can survive with low concentrations of nutrients.

\subsubsection{Gammaproteobacteria}

Piscirickettsiaceae were relatively abundant in crustal fluid samples (Fig. 24.1d). This family contains chemolithoautotrophic sulfur-oxidizing bacteria such as Thiomicrospira spp. and Thioalkalimicrobium spp. The detected clones in the Piscirickettsiaceae were closest to Thiomicrospira spp. with up to $96 \%$ similarity. In contrast, Chromatiales were relatively abundant in active and inactive chimney samples (Fig. 24.1d). The closest cultured species to the clones in Chromatiales were Thiohalomonas spp. or Thioalkalispira spp. (up to $94 \%$ similarity), which are chemolithoautotrophic sulfur-oxidizing bacteria. Members in Chromatiales are facultative anaerobes, which can grow using nitrate as an electron acceptor. In contrast, Thiomicrospira spp. within the Piscirickettsiaceae are strict aerobes. Therefore, the availability of electron acceptors is likely to lead to differences in the relative abundance of the two taxa of sulfur-oxidizing bacteria.
Alteromonadales were relatively abundant in crustal fluid samples and the natural vent fluid sample (Fig. 24.1d). The detected clones in the Alteromonadales were close to Alteromonas spp., Pseudoalteromonas spp., Marinobacter spp., etc. (up to $99 \%$ similarity). These cultured species are mainly chemoorganoheterotrophs. These species may thrive in warm crustal fluids $\left(<40{ }^{\circ} \mathrm{C}\right)$ under the seafloor using organic carbon produced by chemolithoautotrophs. The gammaproteobacterial population of the F2apm1 sample differed from those of the other crustal fluid samples (Fig. 24.1d).

\subsubsection{Deltaproteobacteria}

Deltaproteobacteria accounted for over $10 \%$ of the total number of clones in 3 out of 4 active chimney samples (Fig. 24.1b, e). Most of the deltaproteobacterial clones from the active chimney samples were affiliated with the Desulfobulbaceae, of which members grow depending on the reduction of oxidized sulfur species (such as sulfate and thiosulfate) or sulfur disproportionation. The closest cultured species to these clones are Desulfobulbus spp., Desulfocapsa spp., etc. (92-97 \% similarity). Desulfobulbaceae have been also detected in active chimneys in other hydrothermal fields, such as the hydrothermal fields in the Okinawa Trough, Suiyo Seamount and $9^{\circ} \mathrm{N}$ EPR (Kato et al. 2013; Kormas et al. 2006; Nakagawa et al. 2004). In contrast, Desulfobulbaceae were rarely detected in the other SMT samples and in inactive chimneys in other hydrothermal fields, such as the hydrothermal fields in the Okinawa Trough, Central Indian Ridge (CIR) and $9^{\circ} \mathrm{N}$ EPR (Suzuki et al. 2004; Sylvan et al. 2012). These facts suggest that the detected members in Desulfobulbaceae prefer conditions in the active chimneys.

In contrast, Nitrospinaceae were detected in all of the inactive chimneys and iron-rich mat samples (Fig. 24.1e). A nitrite-oxidizing bacterium, Nitrospina gracilis is the sole cultured species in Nitrospinaceae (Watson and Waterbury 1971). It should be noted that a novel phylum, Nitrospinae has been proposed on the basis of a detailed phylogenetic analysis of the genome sequence of $N$. gracilis (Lücker et al. 2013). The detected members in the Nitrospinaceae may use nitrite as an electron donor. Nitrate reducers, e.g., members in Chromatiales, can produce nitrite. Remarkably, both Nitrospinaceae and Chromatiales were relatively abundant in the inactive chimney samples, suggesting that redox cycling of nitrogen species is potentially driven by the combination of nitrite oxidizers in the Nitrospinaceae and nitrate reducers in the Chromatiales. 


\subsubsection{Epsilonproteobacteria}

Epsilonproteobacteria accounted for over $15 \%$ of the total number of clones in all the active chimney samples (Fig. 24.1b, f). They are likely to play a significant role as primary producers in the ecosystem within the active chimneys in the SMT. This class contains chemolithoautotrophs using hydrogen and/or reduced sulfur species as electron donors (Campbell et al. 2006). The high proportions of Epsilonproteobacteria and Desulfobulbaceae in the Deltaproteobacteria in the clone libraries from the active chimney samples suggest that they contribute to the redox cycling of sulfur.

Epsilonproteobacteria were also detected in some crustal fluid samples (Fig. 24.1b, f). Hydrogen sulfide was detected in the crustal fluids $(\sim 5 \mu \mathrm{M}$; Toki et al. Chap. 45). These results suggest that, in addition to iron, the reduced sulfur species is used as an energy source for prokaryotic communities in the crustal fluids below the seafloor. In contrast, Epsilonproteobacteria were rarely detected in the iron-rich mat samples, suggesting that hydrogen and reduced sulfur species are not available in these habitats. Instead, iron may be the major energy source for prokaryotic communities in the iron-rich mats as mentioned above.

Epsilonproteobacteria were detected but only in low numbers in two inactive chimney samples, even though reduced sulfur species were rich in the chimneys. This suggests that the detected Epsilonproteobacteria cannot use the reduced sulfur species in the inactive chimneys surveyed. Alternatively, conditions, such as temperature, $\mathrm{pH}$ and $\mathrm{Eh}$, in the inactive chimneys might not be suitable for Epsilonproteobacteria. In fact, autotrophs within the Epsilonproteobacteria use the reductive tricarboxylic acid cycle for carbon fixation, and this cycle appears to be the dominant pathway in habitats characterized by warm (over $20{ }^{\circ} \mathrm{C}$ ) and anaerobic (or microaerobic) conditions (Nakagawa and Takai 2008; Hügler and Sievert 2010).

\subsubsection{Bacteroidetes}

Bacteroidetes were relatively abundant in the clone libraries from the active and inactive chimney samples (Fig. 24.1a, g). In particular, most of the clones detected in one inactive chimney (IYdc) were classified as belonging to the VC21_Bac22 group. This group was also detected in some of the other active and inactive chimney samples (Fig. 24.1g). The clones in this group are distant from the closest cultured species $(<90 \%$ similarity). The group was found to be relatively abundant in some inactive chimneys at other hydrothermal fields (Suzuki et al. 2004; Sylvan et al. 2012). Furthermore, this group was also relatively abundant in the clone libraries from massive sub-seafloor sulfide deposits collected in the SMT using BMS (S. Kato, in preparation). These results imply that the appearance of this group is related to the presence of sulfide minerals.

\subsubsection{Uncultured Bacterial Clone Groups}

The uncultured clone groups detected in the SMT samples were affiliated with GN02, GN04, KSB1, NPL-UPA2, OD1, OP1, OP3, PAUC34f, SAR406, SBR1093, TM6, TM7 and WS3. Metagenomic analyses have shown the metabolic potential of some groups, i.e., OD1 (Wrighton et al. 2012), OP1 (Takami et al. 2012), TM6 (McLean et al. 2013) and TM7 (Marcy et al. 2007). Furthermore, a recent study has reported the near-complete genomes of GN02, OP3, SAR406 and WS3, in addition to OD1 and OP1, using single-cell genomic analysis; however, details of metabolic potential have not been described yet (Rinke et al. 2013). Further cultivation or metagenomic analysis is needed to elucidate the metabolic function of the uncultured groups detected in the SMT.

\subsection{Archaeal Community Structures}

Diverse archaeal 16S rRNA gene sequences were detected in the SMT samples (Fig. 24.2 and Suppl. 24.2). In addition to cultured thermophilic Euryarchaeota and Crenarchaeota that are typical in deep-sea hydrothermal vents, the following groups were detected: Marine benthic groups $\mathrm{A}$ and $\mathrm{E}$ (MBGA and MBGE), Marine groups I, II and III (MGI, MGII and MGIII), Marine hydrothermal vent groups (MHVG and MHVG-1), Deep-sea euryarchaeotic group (DSEG), Deep-sea hydrothermal vent euryarchaeotic group (DHVEG) and Terrestrial hot spring crenarchaeotic group (THSCG). The dominant taxonomic groups for each sample type are shown in Table 24.1.

\subsubsection{Thermophilic Archaea and Related Groups}

Clones closely related to cultured thermophiles in the Euryarchaeota and Crenarchaeota, such as members in Thermococci, Archaeoglobi and Thermopreotei, were detected only in the active chimney samples (Fig. 24.2a). These cultured archaea include hydrogen-oxidizers, $S^{0}$ reducers, sulfate-reducers and fermenters. In addition, Korarchaeota were detected only in one active chimney sample (AFhm). Whole genome analyses have revealed that the Korarchaeota contains peptide fermenters (Elkins et al. 2008). THSCG was also detected in all of the active chimney samples (Fig. 24.2a). A metagenomic analysis has 


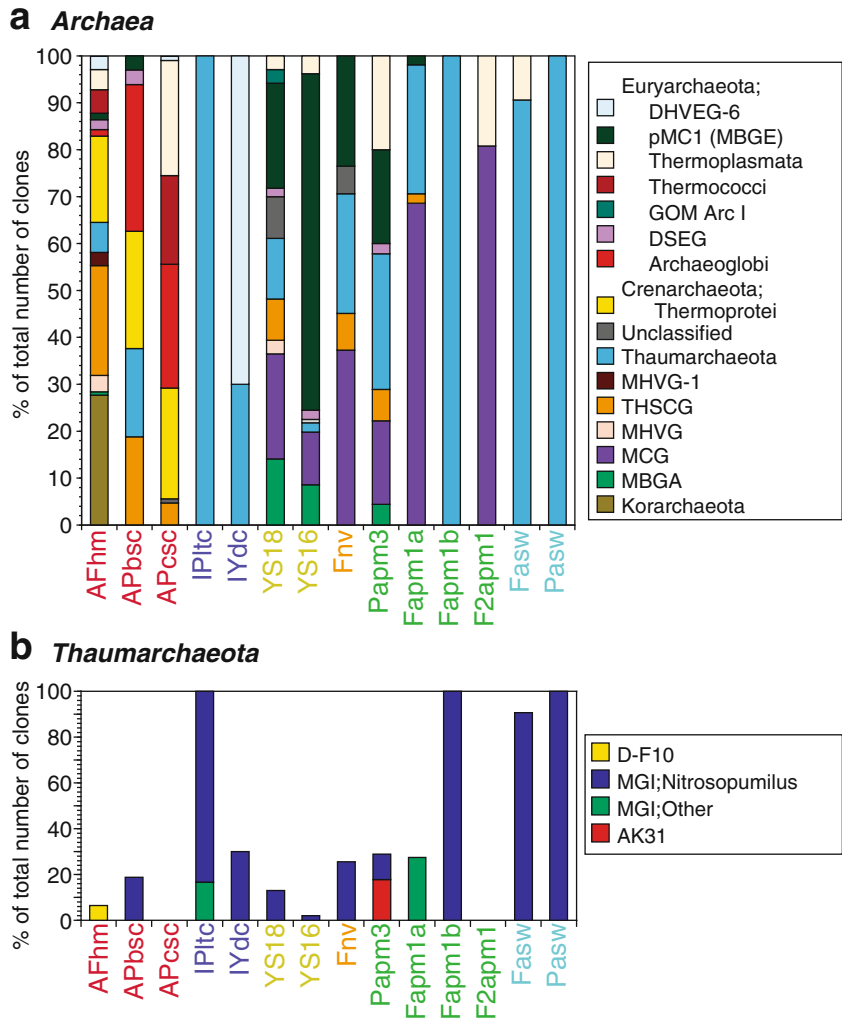

C Thermoplasmata

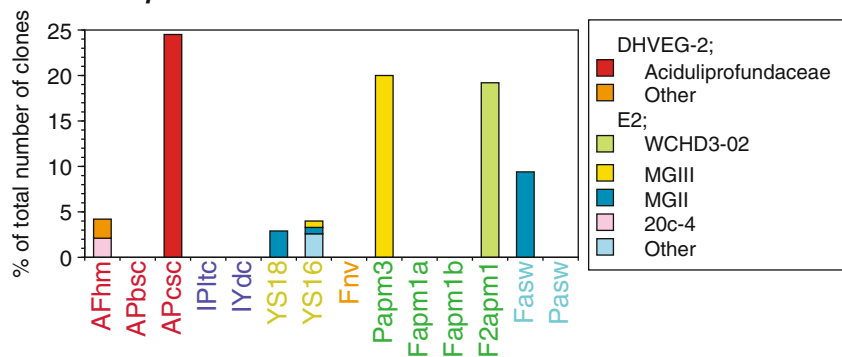

Fig. 24.2 Archaeal community structures based on the 16S rRNA gene clone libraries. The detection frequency of each taxon for (a) Archaea, (b) Thaumarchaeota, and (c) Thermoplasmata are shown. Colors of the sample ID indicate the sample types: red, active chimney; purple, inactive chimney; yellow, iron-rich mat; orange, natural vent fluid; green, crustal fluid; sky-blue, ambient seawater. See also Suppl. Table 24.1 for the sample description

suggested that THSCG contains a hydrogen- or CO-utilizing acetogen (Nunoura et al. 2011). These thermophilic archaea have been widely detected in active chimneys within various hydrothermal fields (Takai et al. 2006).

\subsubsection{Thaumarchaeota and Related Groups}

Thaumarchaeota were detected in most of the samples (Fig. 24.2a). All of the clones of Thaumarchaeota detected in the ambient seawater, the iron-rich mat and the natural vent fluid samples were closely related to Nitrosopumilus maritimus, an ammonia-oxidizer belonging to MGI (Könneke et al. 2005). In contrast, the clones that were not affiliated with MGI but placed in deeper positions within the Thaumarchaeota (AK31 and D-F10 clusters; Suppl. 24.2) were detected in one active chimney (AFhm) and one crustal fluid samples (Papm3) (Fig. 24.2b). These clones are relatively close to the ammonia-oxidizers, e.g., Nitrososphaera spp. (Tourna et al. 2011) or Candidatus "Nitrosocaldus yellowstonii" (De La Torre et al. 2008) (Suppl. 24.2). Furthermore, MBGA were detected in the two iron-rich mat samples and one crustal fluid sample (Papm3) (Fig. 24.2a). This group is related to the pSL12 clade that may contain ammonia oxidizers (Mincer et al. 2007). These putative ammonia-oxidizing archaea potentially play a role as primary producers in prokaryotic ecosystems in the SMT, which is consistent with the high bioavailable energy yields obtained from ammonia oxidation (Kato et al. 2012).

\subsubsection{Thermoplasmata}

Thermoplasmata accounted for over $15 \%$ of the total number of clones in one active sulfide (APcsc) and two crustal fluid samples (Papm3 and F2apm) (Fig. 24.2a, c). Although Thermoplasmata contains methanogens (Dridi et al. 2012; Iino et al. 2013), the detected clones were distant from the methanogens (Suppl. 24.2).

DHVEG-2 was detected in two of the active chimney samples (AFhm and APcsc; Fig. 24.2c). DHVEG-2 is an ubiquitous group in deep-sea hydrothermal vents and contains a thermoacidophilic sulfur- and iron-reducing chemoorganoheterotroph, Aciduliprofundum boonei (Flores et al. 2012b; Reysenbach et al. 2006). The detected members in DHVEG-2 are probably thermophiles as well as Archaeoglobi, Thermopreotei and THSCG.

All of the Thermoplasmata clones detected in two crustal fluid samples (Papm3 and F2apm1) were affiliated with MGIII or the WCHD3-02 cluster, respectively (Fig. 24.2c). Considering the temperature of the habitats where these clones in MGIII and the WCHD3-02 cluster were detected, they may not be thermophiles.

\subsubsection{Other Archaeal Clone Groups}

MBGE accounted for $20 \%$ or higher of the total number of clones in the two iron-rich mats, the natural vent and one of the crustal fluid samples (Papm3), and it was also detected in two active chimney samples (AFhm and APbsc) and another crustal fluid sample (Fapm1a) (Fig. 24.2a). MBGE has been detected in deep-sea sediments including marine hydrothermal fields (e.g., (Nercessian et al. 2005; Vetriani et al. 1999). MBGE was not detected in the inactive chimney samples of 
the SMT, although they dominated in the libraries from inactive chimneys collected from some hydrothermal fields in the Okinawa Trough and CIR (Suzuki et al. 2004).

MCG was detected in the iron-rich mat, the natural vent fluid and the crustal fluid samples except Fapm1b (Fig. 24.2a). The relative abundance was high $(11.2-80.8 \%)$ in each clone library. MCG is abundant and widely distributed in marine sediments (Kubo et al. 2012). Single-cell genome-sequencing analyses suggest that MCG includes an anaerobic protein-degrader (Lloyd et al. 2013). However, the detected MCG clones show up to $83 \%$ similarity with the $16 \mathrm{~S}$ rRNA gene in the MCG genome. Further cultivation or metagenomic analysis is needed to know the ecophysiology of the MCG in the SMT.

DHVEG-6 dominated in the clone library from one inactive chimney sample (IYdc) and was also detected in two active chimney samples (AFhm and APcsc) (Fig. 24.2a). DHVEG-6 has been detected in various environments including acid mines and marine hydrothermal fields (e.g., Baker et al. 2010; Takai and Horikoshi 1999). The metagenome analyses of Candidatus Parvarchaeum spp. in DHVEG-6 suggest that they are aerobic host-associated/ symbiotic archaea interacting with members of cell wallless Thermoplasmatales (Baker et al. 2010). However, clones related to the cell wall-less Thermoplasmatales spp. were not detected in the SMT samples.

\subsection{Comparison of Community Structures}

The PCoA shows that bacterial community structures are similar within the same sample type, except F2apm1 (Fig. 24.3a). This result is generally consistent with the detection pattern of each taxon (Fig. 24.1), especially of each dominant taxon (Table 24.1). In other words, the bacterial community structures are different among the sample types, i.e., habitat types. Epsilonproteobacteria (putative hydrogen-oxidizers and sulfide-oxidizers) were dominant in the libraries from active chimneys, Zetaproteobacteria (putative iron-oxidizers) were dominant in those from ironrich mats, and both Zetaproteobacteria and Epsilonproteobacteria were mainly detected in crustal fluids (Fig. 24.1, Table 24.1). Members of the Zetaproteobacteria and Epsilonproteobacteria may use $\mathrm{H}_{2} \mathrm{~S}$ or $\mathrm{Fe}^{2+}$ dissolved in the venting hydrothermal fluids. Our previous study has shown that the diversity in bacterial community structures is consistent with the thermodynamic calculation of bioavailable energy yields from oxidation of reduced chemical species, such as hydrogen, hydrogen sulfide and iron, for each habitat (Kato et al. 2012).

In addition, the bacterial community structures clearly differed between active and inactive chimney samples (Fig. 24.3a). Epsilonproteobacteria and thermophilic
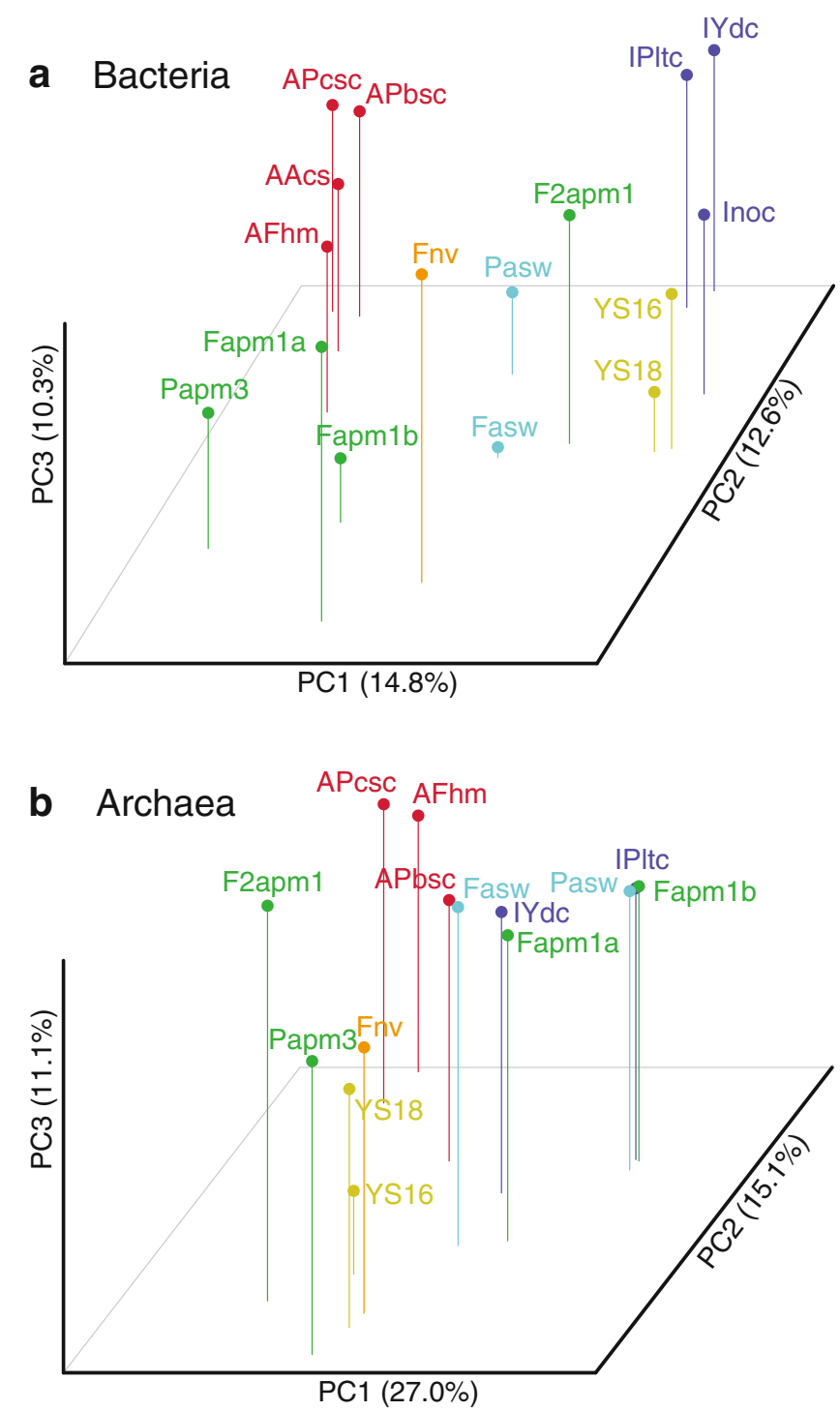

Fig. 24.3 Comparison of (a) bacterial and (b) archaeal community structures by PCoA. The percentages in the axis labels represent the percentages of variation explained by the principal coordinates. Colors of the sample ID indicate the sample types: red, active sulfide chimney; purple, inactive sulfide chimney; yellow, iron-rich mat; orange, natural vent fluid; green, crustal fluid; sky-blue, ambient seawater. See also Suppl. Table 24.1 for the sample description

bacteria (e.g., Aquificae) were rarely detected in the inactive chimneys; Chromatiales in Gammaproteobacteria (putative sulfide-oxidizers) was relatively abundant (Fig. 24.1, Table 24.1). The members in Chromatiales potentially use sulfide minerals such as pyrites, which are the main component of the chimneys (Kakegawa et al. 2008; Ikehata et al., Chap. 22), as their energy sources, even if the supply of hydrothermal fluids ceases. The difference between active and inactive chimney samples may reflect the temporal change before and after the cease of hydrothermal activity, i.e., temperature, $\mathrm{pH}$ and $\mathrm{Eh}$, in addition to availability of 
reduced chemical species (Kato et al. 2010), which is consistent with the previous study of $9^{\circ} \mathrm{N}$ EPR (Sylvan et al. 2012).

In contrast to the bacterial community structures, the archaeal community structures seems not to be clearly distinguished by the sample types, especially for inactive chimneys, some borehole fluids and ambient seawater samples (Fig. 24.3b). MGI was dominant in the libraries from these samples (Fig. 24.2); however, for the present, it is difficult to identify whether the MGI is indigenous in the samples or arises through contamination from the ambient seawater. At the least, archaeal community structures in the active chimneys can be distinguished from those in the other samples (Fig. 24.3b). Thermophilic archaea (e.g., Thermococci and Archaeoglobi) were dominant in the libraries from the active chimney samples (Fig. 24.2, Table 24.1). The detection of thermophilic archaea is consistent with the high temperature of venting fluids from the active chimneys. In contrast, they were rarely detected in the iron-rich mat and crustal fluid samples; MBGE and MCG are mainly detected there (Fig. 24.2, Table 24.1). In addition to temperature, the difference in $\mathrm{pH}$, Eh and availability of reduced chemical species may cause the observed difference in the archaeal communities between the active chimneys and the others, as per the case of the bacterial communities.

\subsection{Concluding Remarks}

These comprehensive comparative analyses show the differences in the prokaryotic community structures among the habitat types on and below the seafloor in the SMT. These differences are likely to be associated with the relative abundance of putative chemolithoautotrophs. The geological difference between the on- and off-ridge hydrothermal sites might not constrain the community structures. Detailed phylogenetic analysis suggests the presence of endemic taxa for each habitat type. The detected prokaryotes are likely to play a significant role in the cycling of carbon, nitrogen, sulfur and/or iron in these habitats. Our results indicate that the prokaryotic community structure in sulfide chimneys dramatically changes before and after cessation of hydrothermal venting. In addition, diverse yet-uncultured bacteria and archaea were detected in the SMT hydrothermal fields. However, DNA-based molecular analyses targeting $16 \mathrm{~S}$ rRNA genes cannot provide direct evidence for physiology, activity or productivity of prokaryotes. Further studies using RNA-based analyses, in situ incubation experiments, isolation and cultivation are needed to understand prokaryotic ecology within the hydrothermal fields.

Acknowledgements We are grateful to two anonymous reviewers for valuable comments and suggestions. This research was funded by the Ministry of Education, Culture, Science, and Technology (MEXT),
Japan, through a special coordination fund (Archaean Park Project: International Research Project on Interaction between Sub-Vent Biosphere and Geo-Environments) and a Grant-in-Aid for Scientific Research on Innovative Areas (Project TAIGA, \#20109006), and partially by the RIKEN Special Postdoctoral Researchers Program.

Open Access This chapter is distributed under the terms of the Creative Commons Attribution Noncommercial License, which permits any noncommercial use, distribution, and reproduction in any medium, provided the original author(s) and source are credited.

\section{References}

Baker BJ, Comolli LR, Dick GJ, Hauser LJ, Hyatt D, Dill BD, Land ML, VerBerkmoes NC, Hettich RL, Banfield JF (2010) Enigmatic, ultrasmall, uncultivated archaea. Proc Natl Acad Sci U S A 107 (19):8806-8811. doi:10.1073/pnas.0914470107

Bazylinski DA, Williams TJ, Lefèvre CT, Trubitsyn D, Fang J, Beveridge TJ, Moskowitz BM, Ward B, Schübbe S, Dubbels BL, Simpson B (2013) Magnetovibrio blakemorei gen. nov., sp. nov., a magnetotactic bacterium (Alphaproteobacteria: Rhodospirillaceae) isolated from a salt marsh. Int $\mathrm{J}$ Syst Evol Microbiol 63(Pt 5):1824-1833. doi:10.1099/ijs.0.044453-0

Campbell BJ, Engel AS, Porter ML, Takai K (2006) The versatile epsilon-proteobacteria: key players in sulphidic habitats. Nat Rev Microbiol 4(6):458-468

Caporaso JG, Kuczynski J, Stombaugh J, Bittinger K, Bushman FD, Costello EK, Fierer N, Pena AG, Goodrich JK, Gordon JI, Huttley GA, Kelley ST, Knights D, Koenig JE, Ley RE, Lozupone CA, McDonald D, Muegge BD, Pirrung M, Reeder J, Sevinsky JR, Turnbaugh PJ, Walters WA, Widmann J, Yatsunenko T, Zaneveld J, Knight R (2010) QIIME allows analysis of high-throughput community sequencing data. Nat Method 7(5):335-336. doi:10. 1038/nmeth.f.303

Cowen J, Giovannoni S, Kenig F, Johnson H, Butterfield D, Rappé M, Hutnak M, Lam P (2003) Fluids from aging ocean crust that support microbial life. Science 299(5603):120-123

Davis R, Moyer C (2008) Extreme spatial and temporal variability of hydrothermal microbial mat communities along the Mariana island arc and southern Mariana back-arc system. J Geophys Res 113: B08S15. doi:10.1029/2007JB005413

Davis RE, Stakes DS, Wheat CG, Moyer CL (2009) Bacterial variability within an iron-silica-manganese-rich hydrothermal mound located off-axis at the Cleft Segment, Juan de Fuca Ridge. Geomicrobiol J 26(8):570-580. doi:10.1080/01490450902889080

De La Torre JR, Walker CB, Ingalls AE, Könneke M, Stahl DA (2008) Cultivation of a thermophilic ammonia oxidizing archaeon synthesizing crenarchaeol. Environ Microbiol 10(3):810-818. doi:10.1111/j.1462-2920.2007.01506.x

Dridi B, Fardeau M-L, Ollivier B, Raoult D, Drancourt M (2012) Methanomassiliicoccus luminyensis gen. nov., sp. nov., a methanogenic archaeon isolated from human faeces. Int J Syst Evol Microbiol 62(Pt 8):1902-1907. doi:10.1099/ijs.0.033712-0

Elkins JG, Podar M, Graham DE, Makarova KS, Wolf Y, Randau L, Hedlund BP, Brochier-Armanet CL, Kunin V, Anderson I, Lapidus A, Goltsman E, Barry K, Koonin EV, Hugenholtz P, Kyrpides N, Wanner G, Richardson P, Keller M, Stetter KO (2008) A korarchaeal genome reveals insights into the evolution of the archaea. Proc Natl Acad Sci U S A 105(23):8102-8107. doi:10. 1073/pnas.0801980105

Emerson D, Rentz JA, Lilburn TG, Davis RE, Aldrich H, Chan C, Moyer CL (2007) A novel lineage of proteobacteria involved in formation of marine Fe-oxidizing microbial mat communities. PLoS One 2(8):e667. doi:10.1371/journal.pone.0000667 
Emerson D, Fleming EJ, McBeth JM (2010) Iron-oxidizing bacteria: an environmental and genomic perspective. Ann Rev Microbiol 64 (1):561-583. doi:10.1146/annurev.micro.112408.134208

Fleming EJ, Davis RE, McAllister SM, Chan CS, Moyer CL, Tebo BM, Emerson D (2013) Hidden in plain sight: discovery of sheathforming, iron-oxidizing Zetaproteobacteria at Loihi Seamount, Hawaii, USA. FEMS Microbiol Ecol 85(1):116-127. doi:10.1111/ 1574-6941.12104

Flores GE, Shakya M, Meneghin J, Yang ZK, Seewald JS, Geoff Wheat C, Podar M, Reysenbach AL (2012a) Inter-field variability in the microbial communities of hydrothermal vent deposits from a backarc basin. Geobiology 10(4):333-346. doi:10.1111/j.1472-4669. 2012.00325.x

Flores GE, Wagner I, Liu Y, Reysenbach A-L (2012b) Distribution, abundance, and diversity patterns of the thermoacidophilic "Deepsea hydrothermal vent euryarchaeota 2" (DHVE2). Front Microbiol 3. doi:10.3389/fmicb.2012.00047

Forget NL, Murdock SA, Juniper SK (2010) Bacterial diversity in Ferich hydrothermal sediments at two South Tonga Arc submarine volcanoes. Geobiology 8(5):417-432. doi:10.1111/j.1472-4669. 2010.00247.x

Guindon S, Dufayard J-F, Lefort V, Anisimova M, Hordijk W, Gascuel O (2010) New algorithms and methods to estimate maximumlikelihood phylogenies: assessing the performance of PhyML 3.0. Syst Biol 59(3):307-321. doi:10.1093/sysbio/syq010

Hodges TW, Olson JB (2009) Molecular comparison of bacterial communities within iron-containing flocculent mats associated with submarine volcanoes along the Kermadec Arc. Appl Environ Microbiol 75(6):1650-1657. doi:10.1128/aem.01835-08

Huber JA, Johnson HP, Butterfield DA, Baross JA (2006) Microbial life in ridge flank crustal fluids. Environ Microbiol 8(1):88-99

Hügler M, Sievert SM (2010) Beyond the calvin cycle: autotrophic carbon fixation in the ocean. Ann Rev Mar Sci 3(1):261-289. doi:10.1146/annurev-marine-120709-142712

Iino T, Tamaki H, Tamazawa S, Ueno Y, Ohkuma M, Suzuki K, Igarashi Y, Haruta S (2013) Candidatus Methanogranum caenicola: a novel methanogen from the anaerobic digested sludge, and proposal of Methanomassiliicoccaceae fam. nov. And Methanomassiliicoccales ord. nov., for a methanogenic lineage of the class Thermoplasmata. Microbes Environ 28(2):244-250

Kakegawa T, Utsumi M, Marumo K (2008) Geochemistry of sulfide chimneys and basement pillow lavas at the Southern Mariana Trough $\left(12.55^{\circ} \mathrm{N}-12.58^{\circ} \mathrm{N}\right)$. Res Geol 58:249-266

Kato S, Kobayashi C, Kakegawa T, Yamagishi A (2009a) Microbial communities in iron-silica-rich microbial mats at deep-sea hydrothermal fields of the Southern Mariana Trough. Environ Microbiol 11(8):2094-2111

Kato S, Yanagawa K, Sunamura M, Takano Y, Ishibashi J, Kakegawa T, Utsumi M, Yamanaka T, Toki T, Noguchi T, Kobayashi K, Moroi A, Kimura H, Kawarabayasi Y, Marumo K, Urabe T, Yamagishi A (2009b) Abundance of Zetaproteobacteria within crustal fluids in back-arc hydrothermal fields of the Southern Mariana Trough. Environ Microbiol 11(12):3210-3222

Kato S, Takano Y, Kakegawa T, Oba H, Inoue K, Kobayashi C, Utsumi M, Marumo K, Kobayashi K, Ito Y, Ishibashi J, Yamagishi A (2010) Biogeography and biodiversity in sulfide structures of active and inactive vents at deep-sea hydrothermal fields of the Southern Mariana Trough. Appl Environ Microbiol 76(9):2968-2979. doi:10. 1128/aem.00478-10

Kato S, Nakamura K, Toki T, Ishibashi J, Tsunogai U, Hirota A, Ohkuma M, Yamagishi A (2012) Iron-based microbial ecosystem on and below the seafloor: a case study of hydrothermal fields of the Southern Mariana Trough. Front Microbiol 3. doi:10.3389/ fmicb.2012.00089

Kato S, Nakawake M, Kita J, Yamanaka T, Utsumi M, Okamura K, Ishibashi J, Ohkuma M, Yamagishi A (2013) Characteristics of microbial communities in crustal fluids in a deep-sea hydrothermal field of the Suiyo Seamount. Front Microbiol 4. doi:10.3389/ fmicb.2013.00085

Könneke M, Bernhard AE, de la Torre JR, Walker CB, Waterbury JB, Stahl DA (2005) Isolation of an autotrophic ammonia-oxidizing marine archaeon. Nature 437(7058):543-546

Kormas KA, Tivey MK, Von Damm K, Teske A (2006) Bacterial and archaeal phylotypes associated with distinct mineralogical layers of a white smoker spire from a deep-sea hydrothermal vent site $\left(9^{\circ} \mathrm{N}\right.$, East Pacific Rise). Environ Microbiol 8(5):909-920. doi:10.1111/j. 1462-2920.2005.00978.x

Kubo K, Lloyd KG, Biddle JF, Amann R, Teske A, Knittel K (2012) Archaea of the miscellaneous crenarchaeotal group are abundant, diverse and widespread in marine sediments. ISME J. doi:10.1038/ ismej.2012.37

Li J, Zhou H, Peng X, Wu Z, Chen S, Fang J (2012) Microbial diversity and biomineralization in low-temperature hydrothermal iron-silicarich precipitates of the Lau Basin hydrothermal field. FEMS Microbiol Ecol 81(1):205-216. doi:10.1111/j.1574-6941.2012. 01367.x

Lloyd KG, Schreiber L, Petersen DG, Kjeldsen KU, Lever MA, Steen AD, Stepanauskas R, Richter M, Kleindienst S, Lenk S, Schramm A, Jorgensen BB (2013) Predominant archaea in marine sediments degrade detrital proteins. Nature 496(7444):215-218. doi:10.1038/ nature 12033

Lozupone C, Knight R (2005) UniFrac: a new phylogenetic method for comparing microbial communities. Appl Environ Microbiol 71(12):8228-8235. doi:10.1128/aem.71.12.8228-8235.2005

Lücker S, Nowka B, Rattei T, Spieck E, Daims H (2013) The genome of Nitrospina gracilis illuminates the metabolism and evolution of the major marine nitrite oxidizer. Front Microbiol 4. doi:10.3389/ fmicb.2013.00027

Marcy Y, Ouverney C, Bik EM, Losekann T, Ivanova N, Martin HG, Szeto E, Platt D, Hugenholtz P, Relman DA, Quake SR (2007) Dissecting biological "Dark matter" with single-cell genetic analysis of rare and uncultivated TM7 microbes from the human mouth. Proc Natl Acad Sci U S A 104(29):11889-11894. doi:10.1073/pnas. 0704662104

Marumo K, Urabe T, Goto A, Takano Y, Nakaseama M (2008) Mineralogy and isotope geochemistry of active submarine hydrothermal field at Suiyo Seamount, Izu-Bonin Arc, west Pacific Ocean. Res Geol 58(3):220-248. doi:10.1111/j.1751-3928.2008.00059.x

McAllister SM, Davis RE, McBeth JM, Tebo BM, Emerson D, Moyer CL (2011) Biodiversity and emerging biogeography of the neutrophilic iron-oxidizing Zetaproteobacteria. Appl Environ Microbiol 77(15):5445-5457. doi:10.1128/aem.00533-11

McLean JS, Lombardo M-J, Badger JH, Edlund A, Novotny M, Yee-Greenbaum J, Vyahhi N, Hall AP, Yang Y, Dupont CL, Ziegler MG, Chitsaz H, Allen AE, Yooseph S, Tesler G, Pevzner PA, Friedman RM, Nealson KH, Venter JC, Lasken RS (2013) Candidate phylum TM6 genome recovered from a hospital sink biofilm provides genomic insights into this uncultivated phylum. Proc Natl Acad Sci U S A. doi:10.1073/pnas.1219809110

Mincer TJ, Church MJ, Taylor LT, Preston C, Karl DM, DeLong EF (2007) Quantitative distribution of presumptive archaeal and bacterial nitrifiers in Monterey Bay and the North Pacific Subtropical Gyre. Environ Microbiol 9(5):1162-1175. doi:10.1111/j.14622920.2007.01239.x

Nakagawa S, Takai K (2008) Deep-sea vent chemoautotrophs: diversity, biochemistry and ecological significance. FEMS Microbiol Ecol 65(1):1-14

Nakagawa T, Nakagawa S, Inagaki F, Takai K, Horikoshi K (2004) Phylogenetic diversity of sulfate-reducing prokaryotes in active deep-sea hydrothermal vent chimney structures. FEMS Microbiol Lett 232(2):145-152

Nakagawa S, Takai K, Inagaki F, Chiba H, Ishibashi J, Kataoka S, Hirayama H, Nunoura T, Horikoshi K, Sako Y (2005) Variability in microbial community and venting chemistry in a sediment-hosted 
backarc hydrothermal system: impacts of subseafloor phaseseparation. FEMS Microbiol Ecol 54(1):141-155

Nercessian O, Fouquet Y, Pierre C, Prieur D, Jeanthon C (2005) Diversity of bacteria and archaea associated with a carbonate-rich metalliferous sediment sample from the rainbow vent field on the Mid-Atlantic Ridge. Environ Microbiol 7(5):698-714

Nunoura T, Takaki Y, Kakuta J, Nishi S, Sugahara J, Kazama H, Chee G-J, Hattori M, Kanai A, Atomi H, Takai K, Takami H (2011) Insights into the evolution of archaea and eukaryotic protein modifier systems revealed by the genome of a novel archaeal group. Nucl Acids Res 39(8):3204-3223. doi:10.1093/nar/gkq1228

Orcutt BN, Bach W, Becker K, Fisher AT, Hentscher M, Toner BM, Wheat CG, Edwards KJ (2011) Colonization of subsurface microbial observatories deployed in young ocean crust. ISME J 5 (4):692-703. doi:10.1038/ismej.2010.157

Øvreås L, Johannessen T, Jorgensen S, Thorseth IH, Pedersen RB (2007) Diversity of microorganisms associated with low temperature iron deposits at the $71^{\circ} \mathrm{N}$ hydrothermal vent field along the arctic mid-ocean ridge. Eos Trans AGU 88(52) Fall Meet Suppl, Abstract OS43A-0992

Quast C, Pruesse E, Yilmaz P, Gerken J, Schweer T, Yarza P, Peplies J, Glöckner FO (2012) The SILVA ribosomal RNA gene database project: improved data processing and web-based tools. Nucl Acids Res. doi:10.1093/nar/gks1219

Reysenbach A-L, Liu Y, Banta AB, Beveridge TJ, Kirshtein JD, Schouten S, Tivey MK, Von Damm KL, Voytek MA (2006) A ubiquitous thermoacidophilic archaeon from deep-sea hydrothermal vents. Nature 442(7101):444-447

Rinke C, Schwientek P, Sczyrba A, Ivanova NN, Anderson IJ, Cheng J-F, Darling A, Malfatti S, Swan BK, Gies EA, Dodsworth JA, Hedlund BP, Tsiamis G, Sievert SM, Liu W-T, Eisen JA, Hallam SJ, Kyrpides NC, Stepanauskas R, Rubin EM, Hugenholtz P, Woyke T (2013) Insights into the phylogeny and coding potential of microbial dark matter. Nature 499(7459):431-437. doi:10.1038/nature12352

Santelli CM, Orcutt BN, Banning E, Bach W, Moyer CL, Sogin ML, Staudigel H, Edwards KJ (2008) Abundance and diversity of microbial life in ocean crust. Nature 453(7195):653-656

Schloss PD, Westcott SL, Ryabin T, Hall JR, Hartmann M, Hollister EB, Lesniewski RA, Oakley BB, Parks DH, Robinson CJ, Sahl JW, Stres B, Thallinger GG, Van Horn DJ, Weber CF (2009) Introducing mothur: open-source, platform-independent, community-supported software for describing and comparing microbial communities. Appl Environ Microbiol 75 (23):7537-7541. doi:10.1128/aem.01541-09

Schrenk MO, Kelley DS, Delaney JR, Baross JA (2003) Incidence and diversity of microorganisms within the walls of an active deep-sea sulfide chimney. Appl Environ Microbiol 69(6):3580-3592

Suzuki Y, Inagaki F, Takai K, Nealson KH, Horikoshi K (2004) Microbial diversity in inactive chimney structures from deep-sea hydrothermal systems. Microb Ecol 47(2):186-196

Sylvan JB, Toner BM, Edwards KJ (2012) Life and death of deep-sea vents: bacterial diversity and ecosystem succession on inactive hydrothermal sulfides. MBio 3(1):e00279-11. doi:10.1128/mBio. 00279-11

Takai K, Horikoshi K (1999) Genetic diversity of archaea in deep-sea hydrothermal vent environments. Genetics 152(4):1285-1297

Takai K, Nakagawa S, Reysenbach AL, Hoek J (2006) Microbial ecology of mid-ocean ridges and back-arc basins. Geophys Monogr 166:185-213

Takami H, Noguchi H, Takaki Y, Uchiyama I, Toyoda A, Nishi S, Chee G-J, Arai W, Nunoura T, Itoh T, Hattori M, Takai K (2012) A deeply branching thermophilic bacterium with an ancient acetylCoA pathway dominates a subsurface ecosystem. PLoS One 7(1): e30559. doi:10.1371/journal.pone.0030559

Tourna M, Stieglmeier M, Spang A, Könneke M, Schintlmeister A, Urich T, Engel M, Schloter M, Wagner M, Richter A, Schleper C (2011) Nitrososphaera viennensis, an ammonia oxidizing archaeon from soil. Proc Natl Acad Sci U S A 108(20):8420-8425. doi:10. 1073/pnas. 1013488108

Vetriani C, Jannasch HW, MacGregor BJ, Stahl DA, Reysenbach A-L (1999) Population structure and phylogenetic characterization of marine benthic archaea in deep-sea sediments. Appl Environ Microbiol 65(10):4375-4384

Watson S, Waterbury J (1971) Characteristics of two marine nitrite oxidizing bacteria, Nitrospina gracilis nov. gen. nov. sp. and Nitrococcus mobilis nov. gen. nov. sp. Arch Mikrobiol 77 (3):203-230. doi:10.1007/bf00408114

Wrighton KC, Thomas BC, Sharon I, Miller CS, Castelle CJ, VerBerkmoes NC, Wilkins MJ, Hettich RL, Lipton MS, Williams KH, Long PE, Banfield JF (2012) Fermentation, hydrogen, and sulfur metabolism in multiple uncultivated bacterial phyla. Science 337(6102):1661-1665. doi:10.1126/science.1224041 